\title{
Effect of parsley (Petroselinum crispum) intake on urinary apigenin excretion, blood antioxidant enzymes and biomarkers for oxidative stress in human subjects
}

\author{
S. E. Nielsen ${ }^{1}$, J. F. Young ${ }^{2}$, B. Daneshvar ${ }^{1}$, S. T. Lauridsen ${ }^{1}$, P. Knuthsen ${ }^{3}$, B. Sandström ${ }^{2}$ and \\ L. O. Dragsted ${ }^{1 *}$ \\ ${ }^{1}$ Institute of Food Safety and Toxicology, Danish Veterinary and Food Administration, Copenhagen, Denmark \\ ${ }^{2}$ Research Department of Human Nutrition, Royal Veterinary and Agricultural University, Frederiksberg, Denmark \\ ${ }^{3}$ Institute of Food Chemistry and Nutrition, Danish Veterinary and Food Administration, Copenhagen, Denmark
}

(Received 9 April 1998 - Revised 5 November 1998 - Accepted 22 December 1998)

\begin{abstract}
Seven men and seven women participated in a randomized crossover trial to study the effect of intake of parsley (Petroselinum crispum), containing high levels of the flavone apigenin, on the urinary excretion of flavones and on biomarkers for oxidative stress. The subjects received a strictly controlled diet low in flavones and other naturally occurring antioxidants during the 2 weeks of intervention. This basic diet was supplemented with parsley providing $3.73-4.49 \mathrm{mg}$ apigenin/MJ in one of the intervention weeks. Urinary excretion of apigenin was 1.59-409.09 $\mu \mathrm{g} / \mathrm{MJ}$ per $24 \mathrm{~h}$ during intervention with parsley and $0-112 \cdot 27 \mu \mathrm{g} / \mathrm{MJ}$ per $24 \mathrm{~h}$ on the basic $\operatorname{diet}(P<0 \cdot 05)$. The fraction of apigenin intake excreted in the urine was 0.58 (SE 0.16) \% during parsley intervention. Erythrocyte glutathione reductase $(E C$ 1.6.4.1; GR) and superoxide dismutase $(E C$ 1.15.1.1; SOD) activities increased during intervention with parsley $(P<0.005)$ as compared with the levels on the basic diet, whereas erythrocyte catalase (EC 1.11.1.6) and glutathione peroxidase (EC 1.11.1.9) activities did not change. No significant changes were observed in plasma protein 2-adipic semialdehyde residues, a biomarker of plasma protein oxidation. In this short-term investigation, an overall decreasing trend in the activity of antioxidant enzymes was observed during the 2 -week study. The decreased activity of SOD was strongly correlated at the individual level with an increased oxidative damage to plasma proteins. However, the intervention with parsley seemed, partly, to overcome this decrease and resulted in increased levels of GR and SOD.
\end{abstract}

Apigenin: Antioxidant status: Urinary excretion

Apigenin is a flavone found in vegetables, seasonings (Kühnau, 1976) and oranges (Fernandez de Simon et al. 1992), and it possesses antioxidant activity in vitro (Fraga et al. 1987; van Acker et al. 1996). Potent biological effects of this flavonoid have been described in vitro and in vivo. Apigenin has been ascribed anticarcinogenic (Wei et al. 1989; Birt et al. 1997), anti-inflammatory (Lee et al. 1993) and antimutagenic (Kuo et al. 1992) properties. Thus, development of a biomarker for intake of apigenin is important in order to evaluate the potential health effects of this particular dietary component. There has only been one previously published attempt to determine the urinary excretion of apigenin in human subjects after ingestion of an apigenin-containing camomile (Matricaria recutita) extract
(Tschiersch \& Hölzl, 1993). However, due to lack of specificity and sensitivity the method failed to detect any apigenin in the urine.

Parsley (Petroselinum crispum) contains large amounts of the flavone apigenin (Justesen et al. 1998), and the low concentration of other flavonoids in this plant makes it suitable for an intervention study with a natural source of apigenin.

In the present study we report on the relationship between daily intake of parsley and urinary excretion of apigenin. The antioxidative effect of the parsley intervention was investigated by measuring the activity of erythrocyte antioxidant enzymes. In addition, a biomarker for plasma protein oxidation (protein 2-adipic semialdehyde, AAS) was measured (Daneshvar et al. 1997).

\footnotetext{
Abbreviations: AAS, 2-adipic semialdehyde; CAT, catalase; Gpx, glutathione peroxidase; GR, glutathione reductase; MES, ( $N$-morpholino)ethanesulfonic acid; SOD, superoxide dismutase.

* Corresponding author: Dr L. O. Dragsted, fax +45 339560 01, email lod@vfd.dk
} 


\section{Methods}

\section{Study design and diet}

The study design was a randomized crossover with two 1 -week intervention periods in succession. The basic diet and the intervention diet consisted of three menus consumed each week on days $1+4,2+5+7$ and $3+6$ respectively. The composition of the menus is shown in Table 1. For 1 week the intervention diet included $20 \mathrm{~g}$ parsley/10 MJ per $\mathrm{d}$. Half the parsley was included in a meal and heated in a microwave oven at $650 \mathrm{~W}$ for 3.5-4.5 min depending on portion size, and the remaining $10 \mathrm{~g}$ parsley was consumed fresh. Only the leaves of curled parsley were used for the study. Before use, the parsley was quickly washed in cold water, carefully dried in a cloth and finely chopped in a blender. The diet was composed of common foods selected to comply with a low content of flavonoids and other antioxidants. The calculated macronutrient content and selected micronutrient content of the total diet are given in Table 2 (Dankost). Duplicate portions of all three menus with and without parsley were collected for each group on days 1, 2 and 3, as well as from each batch of parsley used throughout the study. Each sample was frozen at $-20^{\circ}$, and homogenized and lyophilized before analysis. The energy requirement of each subject was estimated from records of food intake by weight for $4 \mathrm{~d}$ as well as body weight and degree of physical activity. Subjects were instructed to record consumed food items individually by weight, including information on fat content, recipes and means of preparation when applicable. All meals were prepared at the Department in individual portions according to energy requirement. One of the daily main meals was taken at the Department while the remaining (cold) meals were provided

Table 1. Composition of the diet $(\mathrm{g} / \mathrm{d})$ at an energy intake of $10 \mathrm{MJ}$

\begin{tabular}{|c|c|c|c|c|}
\hline Meal & Component & Menu 1 & Menu 2 & Menu 3 \\
\hline Breakfast & $\begin{array}{l}\text { Rolls with carrot } \\
\text { Butter } \\
\text { Cheese } \\
\text { Sour milk } \\
\text { Rye bread crumbs }\end{array}$ & $\begin{array}{r}78 \\
6 \\
30 \\
200 \\
30\end{array}$ & $\begin{array}{r}78 \\
6 \\
30 \\
200 \\
30\end{array}$ & $\begin{array}{r}78 \\
6 \\
30 \\
200 \\
30\end{array}$ \\
\hline Lunch & $\begin{array}{l}\text { Rye bread } \\
\text { Butter } \\
\text { Tuna salad } \\
\text { Ham } \\
\text { Egg salad } \\
\text { Turkey } \\
\text { Cottage cheese / ham } \\
\text { Roast beef } \\
\text { Carrot salad }\end{array}$ & $\begin{array}{r}100 \\
8 \\
50 \\
15\end{array}$ & $\begin{array}{r}100 \\
8\end{array}$ & $\begin{array}{r}60 \\
15 \\
155\end{array}$ \\
\hline Dinner & $\begin{array}{l}\text { Beef stew } \\
\text { Mashed potatoes } \\
\text { Cheese sauce } \\
\text { Pasta } \\
\text { Meat sauce } \\
\text { Rice }\end{array}$ & $\begin{array}{l}270 \\
257\end{array}$ & $\begin{array}{r}270 \\
70\end{array}$ & $\begin{array}{r}275 \\
70\end{array}$ \\
\hline Snack & $\begin{array}{l}\text { Rolls with carrot } \\
\text { Cream cheese } \\
\text { Carrot cake } \\
\text { Sponge cake }\end{array}$ & $\begin{array}{r}117 \\
45 \\
51\end{array}$ & $\begin{array}{r}117 \\
45 \\
60\end{array}$ & $\begin{array}{r}117 \\
45 \\
51\end{array}$ \\
\hline Milk & & 250 & 250 & 250 \\
\hline
\end{tabular}

Table 2. Macronutrient and selected micronutrient content of the diet (/d per 10 MJ)

\begin{tabular}{|c|c|}
\hline Nutrient & Quantity \\
\hline Protein & $88 \mathrm{~g}(16 \%$ energy $)$ \\
\hline Fat & $101 \mathrm{~g}$ (39\% energy) \\
\hline Carbohydrate & $252 \mathrm{~g}(45 \%$ energy $))$ \\
\hline Vitamin A & 2980.8 retinol equivalents \\
\hline Vitamin E & $6.0 \alpha$-tocopherol equivalents \\
\hline Vitamin C & $23 \mathrm{mg}$ \\
\hline
\end{tabular}

daily for intake at home. Subjects were instructed to return any leftovers to the Department for weighing and subtraction from planned intake. Freeze-dried coffee powder was provided for preparation of coffee. Coffee intake varied between subjects but was held constant over the 2 weeks. No foods or drinks other than those provided from the Department were allowed. During the $2 \mathrm{~d}$ preceding the 2-week intervention period, the subjects were instructed to exclude flavonoid-containing foods from their diet: tea, wine, spices, and all fruits and vegetables except potatoes.

\section{Subjects}

Fourteen subjects (seven women, seven men) volunteered for the study. Average age was 23 (range 20-31) years and average BMI was 23.2 (range $19 \cdot 5-27 \cdot 8$ ) $\mathrm{kg} / \mathrm{m}^{2}$. None of the subjects was pregnant, lactating, or had any chronic illness, and all were non-smokers. Subjects received oral and written information about the study, and gave their written consent. The study was approved by the local Research Ethics Committee of Copenhagen and Frederiksberg (J. no. KF01-092/96).

\section{Analysis of apigenin in the diet}

HPLC with photo-diode array detection was used to determine and quantify flavonoids in food samples. Mass spectrometric detection was used as verification.

The flavonoids were analysed as aglycones, obtained by acid hydrolysis of freeze-dried food samples $(500 \mathrm{ml} / \mathrm{l}$ methanol, $2 \mathrm{M}-\mathrm{HCl}, 1.6 \mathrm{mg}$ butylated hydroxyanisole $/ \mathrm{ml}$, at $90^{\circ}$ for $4 \mathrm{~h}$ ). The HPLC separation was accomplished on an RP C18 column with a mobile phase of aqueous methanol $(300 \mathrm{ml} / \mathrm{l})$ containing formic acid $(10 \mathrm{ml} / \mathrm{l})(\mathrm{A})$ and $100 \%$ methanol (B), with the gradient $20 \% \mathrm{~B}-86 \% \mathrm{~B}$ $(\mathrm{v} / \mathrm{v})$ in $50 \mathrm{~min}$. Ultraviolet spectra were recorded from 220 to $450 \mathrm{~nm}$, and apigenin was quantified at $355 \mathrm{~nm}$. Quantification was based on external standards. For details of the method refer to Justesen et al. (1998). Samples were prepared and analysed repeatedly ( $n 4$ for parsley, $n 6$ for food samples). The limit of detection was $0 \cdot 1 \mathrm{mg}$ apigenin per $100 \mathrm{~g}$ food sample.

\section{Analysis of carotenoids in the diet}

Freeze-dried diet sample ( $5 \mathrm{~g}$; cheese and butter excluded) was placed in a Waring blender (New Hartford, CT, USA)

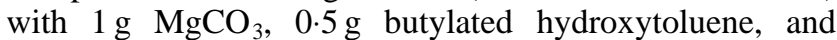
$100 \mathrm{ml}$ ethanol-tetrahydrofuran $(50: 50, \mathrm{v} / \mathrm{v})$. This mixture 
was homogenized for $3 \mathrm{~min}$, and subsequently filtered through a glass filter pad (GF/A Whatman, Maidstone, Kent, UK) in a Büchner funnel. The extraction process was repeated with $100 \mathrm{ml}$ ethanol-tetrahydrofuran. The combined solution of ethanol-tetrahydrofuran was evaporated and the residue redissolved in tetrahydrofuran-mobile phase. The carotenoids, lutein, lycopene, $\alpha$ - and $\beta$-carotene (all obtained from Sigma Chemicals Co., St Louis, MO, USA) and zeaxanthin (from Apin Chemicals Ltd, Oxon., UK), were separated and detected by HPLC with u.v.diode-array detection as described by Hart \& Scott (1995). External standard calibration was used. The HPLC system (Waters, Milford, MA, USA) was equipped with a pump (model 6000A), autoinjector (WISP 710B), u.v. detector (490), and a diode-array detector (996). Waters software Millennium 2010, version 2.10, was used for quantification.

\section{Collection and preparation of urine samples}

Urine samples were collected over $24 \mathrm{~h}$ (from 08.00 hours to 07.59 hours the next morning) from the day before the intervention started (day 0) and on days 1, 7, 8, 9, 11 and 14 of the intervention period. The procedure for making $24 \mathrm{~h}$ urine collections was explained in detail, and the importance of reporting any errors in the urine collection was stressed daily to the subjects. Any failures in urine collection were noted daily, when the subjects delivered their urine samples. The urine samples were collected in 2.5-litre plastic bottles and kept in darkness during collection. $\mathrm{HCl}(1 \mathrm{~mol} / \mathrm{l} ; 50 \mathrm{ml})$ and $10 \mathrm{ml}$ ascorbic acid (100 g/l) were added to each $2 \cdot 5$ litre bottle to increase stability during collection. Urine samples were weighed, their density measured, and $\mathrm{pH}$ adjusted to 3-4 with $1 \mathrm{M}-\mathrm{HCl}$. Portions of $250 \mathrm{ml}$ were stored at $-20^{\circ}$ until analysis.

\section{HPLC analyses of urine samples for apigenin}

Apigenin was determined in the urine samples as described by Nielsen \& Dragsted (1998). Briefly, portions of $15 \mathrm{ml}$ urine to which $5 \mu \mathrm{g}$ 5,7,8-trihydroxyflavone was added as internal standard, were enzymically hydrolysed using $\beta$ glucuronidase $(E C$ 3.2.1.31) and arylsulfatase $(E C$ 3.1.6.1) to release apigenin from glucuronic and sulfate conjugates. After hydrolysis, the samples were applied to solid-phase extraction using Bond Elut C-18 cartridges $(500 \mathrm{mg})$. Each cartridge was washed with $3 \mathrm{ml}$ methanol $(50 \mathrm{ml} / 1$ containing $10 \mathrm{ml}$ formic acid/l) and eluted with $3 \mathrm{ml}$ methanol $(900 \mathrm{ml} / \mathrm{l}$ containing $10 \mathrm{ml}$ formic acid/l and $10 \mathrm{~g}$ ascorbic acid/l) followed by $3 \mathrm{ml}$ pure methanol. The eluates were combined and evaporated to dryness under vacuum. The residue was dissolved in $250 \mu \mathrm{l}$ acetonitrile $(200 \mathrm{ml} / 1$ containing $10 \mathrm{ml}$ formic acid/l) and $100 \mu \mathrm{l}$ was injected onto the HPLC system.

In short, the HPLC system consisted of a Hewlett Packard (Waldbronn, Germany) 1090 system with three pumps, an automatic six-port column switching valve, and diodearray detector. The columns used were a Lichrospher 60 RP-select B, RP-8 $(4 \times 125 \mathrm{~mm}, 5 \mu \mathrm{m})$ column with guard cartridge $(4 \times 4 \mathrm{~mm}, 5 \mathrm{~mm})$ as column 1 and a Purospher $\mathrm{RP}-18(4 \times 125 \mathrm{~mm}, 5 \mu \mathrm{m})$ column with guard cartridge $(4 \times$ $4 \mathrm{~mm}, 5 \mathrm{~mm}$ ) as column 2 (Hewlett Packard). Column temperature was maintained constant at $40^{\circ}$ using a thermostatically controlled column compartment. Detection was carried out simultaneously at 290 and $350 \mathrm{~nm}$, with peak scanning between 210 and $600 \mathrm{~nm}$ ( $2 \mathrm{~nm}$ step). The mobile phases used were (flow of $1 \mathrm{ml} / \mathrm{min}$ ): (A) $23.8 \mathrm{mM}$-citric acid adjusted to $\mathrm{pH} 2.00$ with concentrated $\mathrm{H}_{3} \mathrm{PO}_{4}$, (B) $100 \%$ acetonitrile and (C) $100 \%$ methanol. Samples were injected onto column 1 using isocratic elution of mobile phase B in mobile phase A $(200 \mathrm{ml} / \mathrm{l})$. Using the automatic six-port column-switching valve, the target compounds, apigenin and the internal standard 5,7,8-trihydroxyflavone, were eluted onto column 2. By gradient elution of mobile phases $\mathrm{A}$ and $\mathrm{C}$, the target compounds were selectively eluted through the u.v.-detector. Quantification was based on calibration curves achieved from urine samples spiked with standards of different concentrations.

A standard mixture containing $3 \mu \mathrm{g}$ each of apigenin and 5,7,8-trihydroxyflavone was analysed as external standard before and after each series of samples, to assure the reproducibility of the method. The retention times of the external standard showed inter- and intra-day CV of less than $1 \%$ and the peak areas determined varied less than $5 \%$ ( $n$ 20). The limit of detection and quantification of apigenin was $10 \mathrm{ng} / \mathrm{ml}$ urine, determined by spiking of blank urine. A selected urine sample was included in each series of analyses and served quality control purposes. The amount of apigenin detected in this sample was 550 $(\mathrm{SD} 8 \cdot 1) \mathrm{ng} / \mathrm{ml}(n \mathrm{10})$. The recovery of the internal standard, 5,7,8-trihydroxyflavone, was higher than $90 \%$ in all samples. The amount of apigenin detected in each urine sample was individually corrected for analytical loss of the internal standard. Apigenin and acacetin (4'-methoxy-apigenin) added to urine samples $(2500 \mathrm{ng} / 15 \mathrm{ml}$ sample) were found to be stable (defined as $\geq 95 \%$ of initial amount remaining) for at least 12 months when stored at $-20^{\circ}$.

\section{Collection of blood samples and separation of erythrocytes}

Fasting blood samples were collected in the morning of days $1,2,8,9,10$ and 15 of the 2-week intervention period, thus reflecting the preceding $24 \mathrm{~h}$, i.e. sample day 1 reflects baseline concentrations before intervention (day 0) and sample day 15 reflects the last $24 \mathrm{~h}$ of the test period (day 14). The samples are referred to in the text according to the $24 \mathrm{~h}$ they are reflecting. Subjects were instructed to avoid heavy physical activity for $36 \mathrm{~h}$ before blood sampling. Blood samples were collected in EDTA-coated tubes and centrifuged at $1500 \mathrm{~g}$ for $10 \mathrm{~min}$ at room temperature. Plasma was stored at $-20^{\circ}$ until analysis (maximum 3 months). Erythrocytes were washed once with 3 volumes of saline $(9 \mathrm{~g} \mathrm{NaCl} / \mathrm{l})$, resuspended in 1 volume of purified water for lysis, and then stored at $-80^{\circ}$ until analyses (maximum 2 months). Before analysis the lysate was centrifuged at $15000 \mathrm{~g}(3 \mathrm{~min})$ to remove cell debris. The clear haemoglobin layer was used for the analyses of antioxidant enzymes.

\section{Antioxidant enzymes}

Automated assays were performed on a Cobas Mira analyser (Roche, Basel, Switzerland) to determine the activities 
of the antioxidant enzymes superoxide dismutase ( $E C$ 1.15.1.1; SOD), glutathione peroxidase (EC 1.11.1.9; Gpx), glutathione reductase $(E C$ 1.6.4.1; GR) and catalase $(E C$ 1.11.1.6; CAT) in erythrocyte lysates. The activity of the enzymes was related to the amount of haemoglobin in the blood samples. SOD (Randox, Ardmore, UK; catalogue no. SD 125), Gpx (Randox, catalogue no. RS 505) and haemoglobin (Randox, catalogue no. HG 980) were determined using commercially available kits. GR activity and CAT activity were determined according to methods described previously (Wheeler et al. 1990). NADPH, glutathione, FAD, purpald and potassium periodate were purchased from Sigma Chemical Co.

\section{Determination of adipic semialdehyde}

These procedures were performed as previously described by Daneshvar et al. (1997). Briefly, the protein sample (1 mg protein) was dissolved in $0.25 \mathrm{M}$ - $(N$-morpholino)ethanesulfonic acid (MES) buffer, $\mathrm{pH} 6 \cdot 0$, containing $10 \mathrm{~g}$ $\mathrm{SDS} / \mathrm{l}$ and heated for $1 \mathrm{~min}$ at $100^{\circ}$. A solution of $0.25 \mathrm{M}-$ fluoresceinamine in $0.52 \mathrm{M}-\mathrm{NaOH}$ was added, followed by $0.25 \mathrm{M}-\mathrm{NaCNBH}_{3}$ in $0.25 \mathrm{M}-\mathrm{MES} \mathrm{pH} 6.0$, and the mixture was incubated for $1 \mathrm{~h}$ at $37^{\circ}$. The mixture was applied to a G-25 gel filtration column, and the column eluted with MES buffer. The protein fraction was collected and precipitated by addition of TCA. The precipitate was hydrolysed in $6 \mathrm{M}-\mathrm{HCl}$ at $110^{\circ}$ for $24 \mathrm{~h}$, and an internal standard of acetaldehydefluoresceinamine adduct was added. The hydrolysate was filtered and injected into an HPLC with a Purospher RP-18 column $(4 \times 250 \mathrm{~mm}, 5 \mathrm{~mm}$, Hewlett Packard $)$ eluted by a linear gradient of $0-50 \%$ acetonitrile in $2 \mathrm{mM}$-formic acid, $\mathrm{pH} 3 \cdot 2$. The eluate was monitored at $454 \mathrm{~nm}$, the absorption maximum of decarboxylated fluoresceinamine, and at $275 \mathrm{~nm}$ for determination of free L-tyrosine, a marker for the quantity of hydrolysed protein. The result was corrected for protein hydrolysis and recovery of internal standard.

\section{Statistics}

Contents of apigenin, lutein, $\alpha$-carotene and $\beta$-carotene in the seven samples each of basic and parsley diets for groups A and B were compared by Student's $t$ test. The statistical analysis of biomarkers in the crossover study was done according to Armitage \& Berry (1994) and Pocock (1998). Sex differences between males and females in biomarkers (AAS, GR, Gpx, SOD and CAT) were determined by Student's $t$ test on day 0, i.e. before the controlled diets were taken. If there was no significant difference between males and females they were grouped together for the rest of the analysis. This step could not be performed for apigenin excretion, since no excretion was observed on day 0 , so the mean excretion for each volunteer during parsley intervention was used to compare males and females. Period effects were determined by a paired $t$ test of biomarker values obtained on days 1 and 8, i.e. at commencement of the two periods. Effect $\times$ period interactions were determined using the summed response on the last days of intervention, as described by Armitage \& Berry (1994). If there was no difference in these tests between the two groups, it was assumed that influence of period and of order of treatment were minimal, and the effect of the intervention could be determined by paired $t$ tests. Apigenin excretion was not normally distributed, and also showed clear evidence of carry-over into the second period. The effect of intervention was therefore determined by Wilcoxon rank scores test between groups using as a test variable the differences between the apigenin excretion on last day of period I $\left(\mathrm{API}_{\mathrm{I}}\right)$ and on the last day of period II (API $\mathrm{AI}_{\mathrm{II}}$, i.e. $\left(\mathrm{API}_{\mathrm{I}}\right.$ API II). CAT and SOD showed clear evidence of a period effect, and we therefore tested for an effect of intervention by comparing the two group means by $t$ test on the last day of period 1 (day 7). The result of this analysis was not different from the result of a paired $t$ test, and we have therefore presented the statistical test for all biomarkers in the same format in Table 4. Correlation of continuous variables and analyses of class variables between individuals was performed by the general linear models procedure of the SAS program (version 6.12; Statistical Analysis Systems Inc., Cary, NC, USA). Multivariate ANOVA was performed using the general linear models procedure with a repeated statement for the measurements on the same individuals on subsequent days.

\section{Results \\ Participants}

Four women and three men started on the basic diet (group A) and three women and four men started on the parsley diet (group B). The composition of the diet and the content of selected macro- and micronutrients are listed in Tables 1 and 2 . The average daily energy intake was $12 \cdot 1$ (SD 2.4) MJ. The compliance of the subjects with urine collection was found to be 98 (SD 3.6) \% of all collections, as determined by daily interviews where failures in urine collections were noted.

\section{Content of flavonoids and carotenoids in the diet}

The diet used for parsley intervention was identical to the basic diet, except for the inclusion of parsley, either fresh or microwave heated, with meals. Preliminary analyses of the apigenin content of parsley showed that apigenin was stable to microwave heating $(>95 \%)$. The basic diets and the diet used for parsley intervention (excluding cheese and butter) were analysed for content of flavonoids and carotenoids. The diets used for parsley intervention in the two periods of intervention (groups A and B) were found to contain similar amounts of apigenin (see Table 3). No other flavonoids could be detected in the diet, and apigenin was not detected in the basic diet. The contents of the carotenoids lutein, $\alpha$ and $\beta$-carotene in the batches of basic diet used for the two groups were not significantly different. However, the contents of lutein, $\alpha$ - and $\beta$-carotene in the batches of diet used during parsley intervention, and also the sum of these carotenoids, were significantly different between groups A and $\mathrm{B}(P<0.05)$. In both groups the level of $\alpha$-carotene in the parsley diet was significantly lower than in the basic diet $(P<0.05)$. These differences may originate from batch differences of the food items used to prepare the diet, since the menu and the quantities used for intervention in 
Table 3. Content of apigenin and carotenoids in the basic diet and in the diet used for intervention for two groups of subjects, $\mathrm{A}$ and $\mathrm{B} \dagger$

(Mean values and standard deviations for $7 \mathrm{~d}$ of diet intake)

\begin{tabular}{|c|c|c|c|c|c|c|c|c|}
\hline \multirow[b]{3}{*}{ Compound } & \multicolumn{4}{|c|}{ Group A } & \multicolumn{4}{|c|}{ Group B } \\
\hline & \multicolumn{2}{|c|}{$\begin{array}{l}\text { Basic diet } \\
\text { (mg/MJ) }\end{array}$} & \multicolumn{2}{|c|}{$\begin{array}{l}\text { Parsley diet } \\
\text { (mg/MJ) }\end{array}$} & \multicolumn{2}{|c|}{$\begin{array}{l}\text { Basic diet } \\
\text { (mg/MJ) }\end{array}$} & \multicolumn{2}{|c|}{$\begin{array}{l}\text { Parsley diet } \\
\text { (mg/MJ) }\end{array}$} \\
\hline & Mean & SD & Mean & SD & Mean & SD & Mean & $\mathrm{SD}$ \\
\hline Apigenin & $<0.1 \ddagger$ & & $4 \cdot 14^{*}$ & 0.32 & $<0.1 \ddagger$ & & $4.86^{*}$ & 0.56 \\
\hline Lutein & 0.06 & 0.02 & $0.22^{*}$ & 0.03 & 0.05 & 0.01 & $0.29^{*}$ & 0.01 \\
\hline$\alpha$-Carotene & 0.32 & 0.10 & $0.19^{*}$ & 0.07 & 0.33 & 0.05 & $0.27^{*}$ & 0.04 \\
\hline$\beta$-Carotene & 1.15 & 0.38 & 0.71 & 0.32 & 1.09 & 0.20 & $1 \cdot 12$ & 0.14 \\
\hline
\end{tabular}

Mean values were significantly different from those for the basic diet: ${ }^{*} P<0.05$.

†For details of diets, see Table 1. Butter and cheese were excluded from the analysed food samples, but intake of these items was constant throughout the study.

$\ddagger$ Limit of determination in the fresh food sample.

the two groups were identical. Furthermore, as seen in Table 3 , the content of lutein was significantly higher in the diet used for parsley intervention $(P<0.001)$ than in the basic diet, probably due to the high content of this carotenoid in parsley. However, the total carotenoid intakes were not significantly different between the basic diet and the parsley diet used for intervention.

\section{Excretion of apigenin}

Apigenin was detected in all the urine samples collected after parsley intervention (see Fig. 1). The excretion of apigenin was significantly higher during intervention with parsley (range: $20 \cdot 7-5727.3 \mu \mathrm{g} / 24 \mathrm{~h}$ ) than during the basic diet (range: $0-1571.7 \mu \mathrm{g} / 24 \mathrm{~h} ; P<0.05$ ). As seen in Fig. 2, the average urinary excretion of apigenin in $24 \mathrm{~h}$ as a percentage of intake $(0.58$ (SE 0.16$) \%$ ) was similar in both groups. However, substantial variation among the individuals was observed, allowing the classification of a

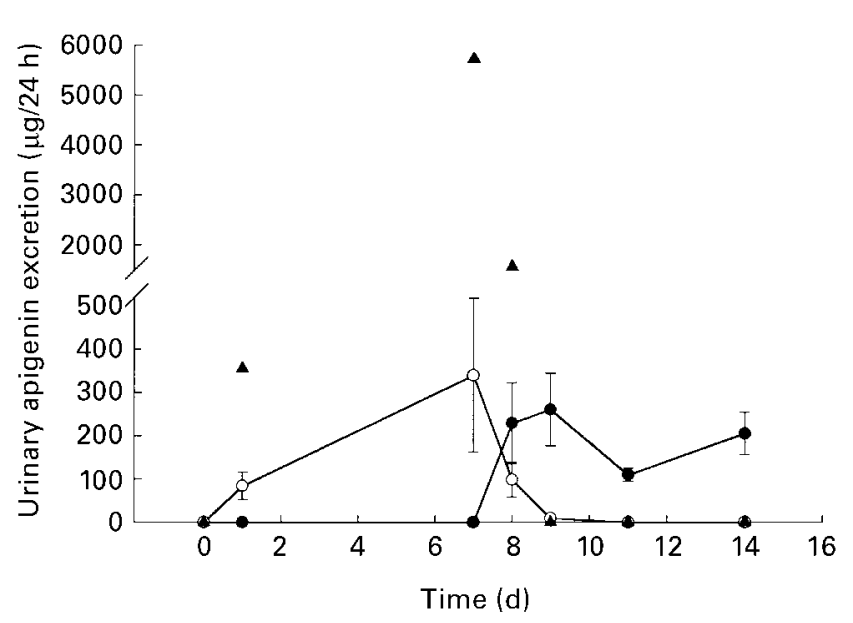

Fig. 1. Urinary apigenin excretion by two groups of subjects consuming a diet containing $20 \mathrm{~g}$ parsley $/ 10 \mathrm{MJ}$ per $\mathrm{d}$ and a basic diet in a crossover design. (๑), Group A, $n 7 ;(\bigcirc)$, group B, $n 6$; $(\mathbf{\Delta})$, outlier no. 1366. Values are means for the individuals in each group, with their standard errors represented by vertical bars. small number of the subjects as high excreters, and of the majority as low excreters. Thus, the average daily apigenin excretion during the parsley intervention for ten of the subjects was between 0.1 and $0.5 \%$ of the apigenin dose, whereas four of the subjects on average excreted between 0.8 and $4.0 \%$ of the dose. The maximum excretion was found in a single individual (shown as an outlier in Figs. 1 and 2) with an excretion as high as $7.45 \%$ of the dose at day 7 of the parsley intervention. No difference between males and females was observed in the mean excretion of apigenin.

There was no excretion of apigenin on the first day on the basic diet after the parsley intervention in four of the individuals in group B, whereas three had low levels of excretion. Thus, urinary excretion and clearance of apigenin seemed to be fast. However, one of the subjects also excreted a small amount of apigenin on the second day after the parsley intervention. Provided that urinary excretion reflects mean blood levels within the collection period, we can calculate the excretion half-life for apigenin to be in

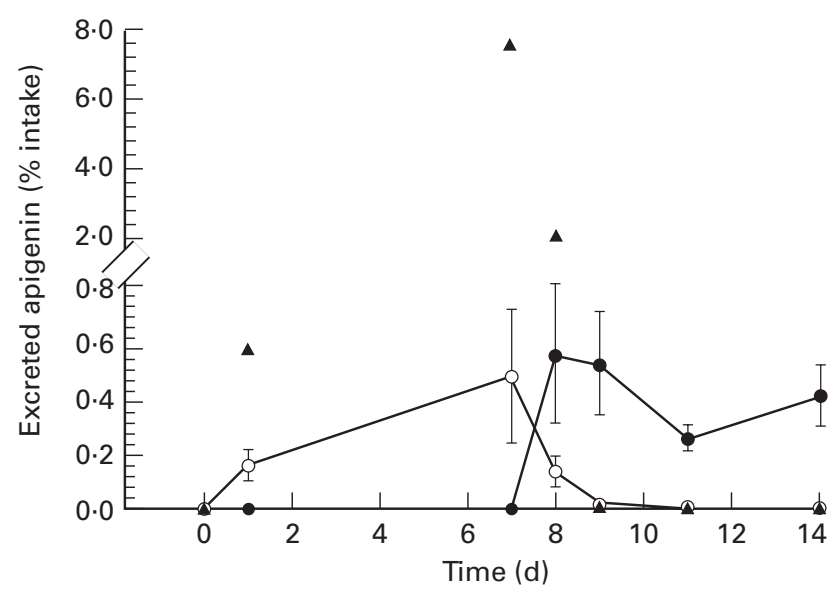

Fig. 2. Urinary apigenin excretion, expressed as a percentage of the dose, in two groups of subjects consuming a diet containing $20 \mathrm{~g}$ parsley/10 MJ per d and a basic diet in a crossover design. (๑), Group A, $n 7 ;(\bigcirc)$, group B, $n 6 ;(\mathbf{\Lambda})$, outlier no. 1366. Values are means for the individuals in each group, with their standard errors represented by vertical bars. 
the order of $12 \mathrm{~h}$. Accordingly, there was no significant time trend increase in apigenin excretion during the week of intervention as determined by multivariate ANOVA, again indicating that most of the ingested apigenin is cleared within $1 \mathrm{~d}$. However, due to the relatively short duration of this study, storage of apigenin in the body without reaching storage limits, would escape detection. Furthermore, apigenin could be converted to another form giving higher absorption than determined in this study. However, the potential metabolite acacetin (4'-methoxyapigenin) was not detected in any of the urine samples (Nielsen \& Dragsted, 1998).

The intake of coffee significantly affected urinary volume $\left(r^{2} 0 \cdot 11, P<0 \cdot 01, n 98\right)$ and the percentage of apigenin excretion $\left(r^{2} 0.09, P<0.01, n 42\right)$ as determined by linear regression analyses of all available data points. However, the coffee intake, and thus the urine volume, was not significantly different between the two periods of intervention.

\section{Biomarkers for oxidative defence}

At baseline, no sex differences with respect to SOD, CAT, GR, Gpx or AAS were observed. Data for males and females were therefore combined. Significant effort $x$ period interactions were observed for Gpx and CAT.

The effects of intervention on the biomarkers for oxidative defence as determined by comparison of biomarker values for the last day on the two diets are shown in Table 4.

There were statistically significant increases in SOD and in GR at the end of intervention $(P<0.005)$, and this was also observed as a significant difference between the two groups in period I alone, indicating that period effects or interactions were not causing these increases. No statistically significant effect by $t$ test or by Wilcoxon's rank score test was observed for Gpx, CAT or AAS.

The individual changes in biomarker values and in coffee consumption were calculated, and correlation analysis was performed between coffee intake and biomarkers. None of the antioxidant enzyme biomarkers was affected by coffee consumption as determined by linear regression analysis.
Interestingly, the excretion of apigenin as a percentage of intake showed a borderline significant correlation with SOD activity and Gpx activity $(P=0.06$ and $P=0.09$ respectively) by linear regression. Furthermore, there was a highly significant correlation between SOD and CAT as well as between SOD and AAS $(P<0 \cdot 01)$. Thus, the individuals who tended to increase with respect to SOD and CAT decreased with respect to AAS and vice versa, indicating a mechanistic connection between the effects on these biomarkers. However, the two groups did not respond equally, again underlining the presence of diet and period interactions.

Analysis of linear effects throughout the intervention period as performed by multivariate ANOVA indicated significant decreases in SOD $(P<0.001)$, CAT $(P<$ $0.001)$, GR $(P<0.01)$ and Gpx activities $(P<0.001$ in males and in females) as well as a non-significant $(P=$ 0.2) increasing trend for AAS (see Fig. 3).

\section{Discussion}

The present study is the first successful investigation of the urinary excretion of the flavone apigenin in human subjects. The only previously published attempt to determine the urinary excretion of apigenin in human subjects after ingestion of an apigenin-containing camomile extract failed to detect any apigenin in the urine due to lack of specificity and sensitivity of the method (Tschiersch \& Hölzl, 1993). Janssen et al. (1998) recently investigated the plasma level of apigenin after intake of $5 \mathrm{~g}$ dried parsley (providing $84 \mathrm{mg}$ apigenin) for $7 \mathrm{~d}$ in a randomized crossover study. However, no plasma apigenin could be detected with a limit of detection of $1.1 \mu \mathrm{mol} / \mathrm{l}$, and the authors concluded that apigenin may not be absorbed at all.

Other previous human studies on flavonoid excretion have primarily been on the flavonol quercetin, found, for example, in apples and onions (Hollman et al. 1995, 1996), but also the flavanone, naringenin, found in citrus fruits has been investigated (Ameer et al. 1996). In the present study we found that apigenin was excreted in urine by human subjects after intake of parsley, and thus, this flavone is absorbable by man. Only a small proportion, 0.58 (SE 0.16$) \%$ of the

Table 4. Urinary apigenin excretion and levels of biomakers for oxidative defence in two groups of subjects ( $\mathrm{A}$ and $\mathrm{B})$ measured on the last day of a 1 -week period on a basic diet or a diet containing parsley†

(Mean values and standard deviations for seven subjects)

\begin{tabular}{|c|c|c|c|c|c|c|c|c|c|c|c|c|}
\hline Biomarker & \multicolumn{4}{|c|}{ Basic diet } & \multicolumn{4}{|c|}{ Parsley diet } & \multicolumn{4}{|c|}{ Paired difference } \\
\hline Plasma AAS (nmol/mg protein) & $22 \cdot 3$ & $3 \cdot 4$ & $26 \cdot 7$ & $14 \cdot 2$ & $27 \cdot 4$ & $5 \cdot 4$ & 19.4 & $6 \cdot 1$ & $5 \cdot 1$ & $8 \cdot 2$ & $-7 \cdot 3$ & $14 \cdot 4$ \\
\hline Urinary apigenin $(\%)^{* *}$ & 0.00 & 0.00 & 0.00 & 0.00 & 0.43 & 0.32 & 1.49 & $2 \cdot 70$ & 0.43 & 0.32 & 1.49 & $2 \cdot 70$ \\
\hline Erythrocyte GR $(\mathrm{U} / \mathrm{g} \mathrm{Hb})^{*}$ & $7 \cdot 29$ & 1.43 & $7 \cdot 35$ & 0.79 & $7 \cdot 18$ & 1.34 & 8.51 & 0.88 & -0.11 & 0.57 & $1 \cdot 16$ & 0.47 \\
\hline Erythrocyte CAT (U/g Hb) & $12 \cdot 2$ & 0.9 & $14 \cdot 0$ & 0.6 & $11 \cdot 8$ & 0.7 & $14 \cdot 8$ & $1 \cdot 0$ & -0.41 & 0.38 & 0.86 & 0.99 \\
\hline
\end{tabular}

AAS, 2-adipic semialdehyde; GR, glutathione reductase; $\mathrm{Hb}$, haemoglobin; Gpx, glutathione peroxidase; SOD, superoxide dismutase; CAT, catalase.

Mean values for parsley diet (groups $\mathrm{A}$ and $\mathrm{B}$ combined) were significantly different from those for basic diet (groups $\mathrm{A}$ and $\mathrm{B}$ combined): ${ }^{*} P<0.05$, ${ }^{\star *} P<0.01$.

$\dagger$ For details of diets and procedures, see Table 1 and pp. 448-450. 


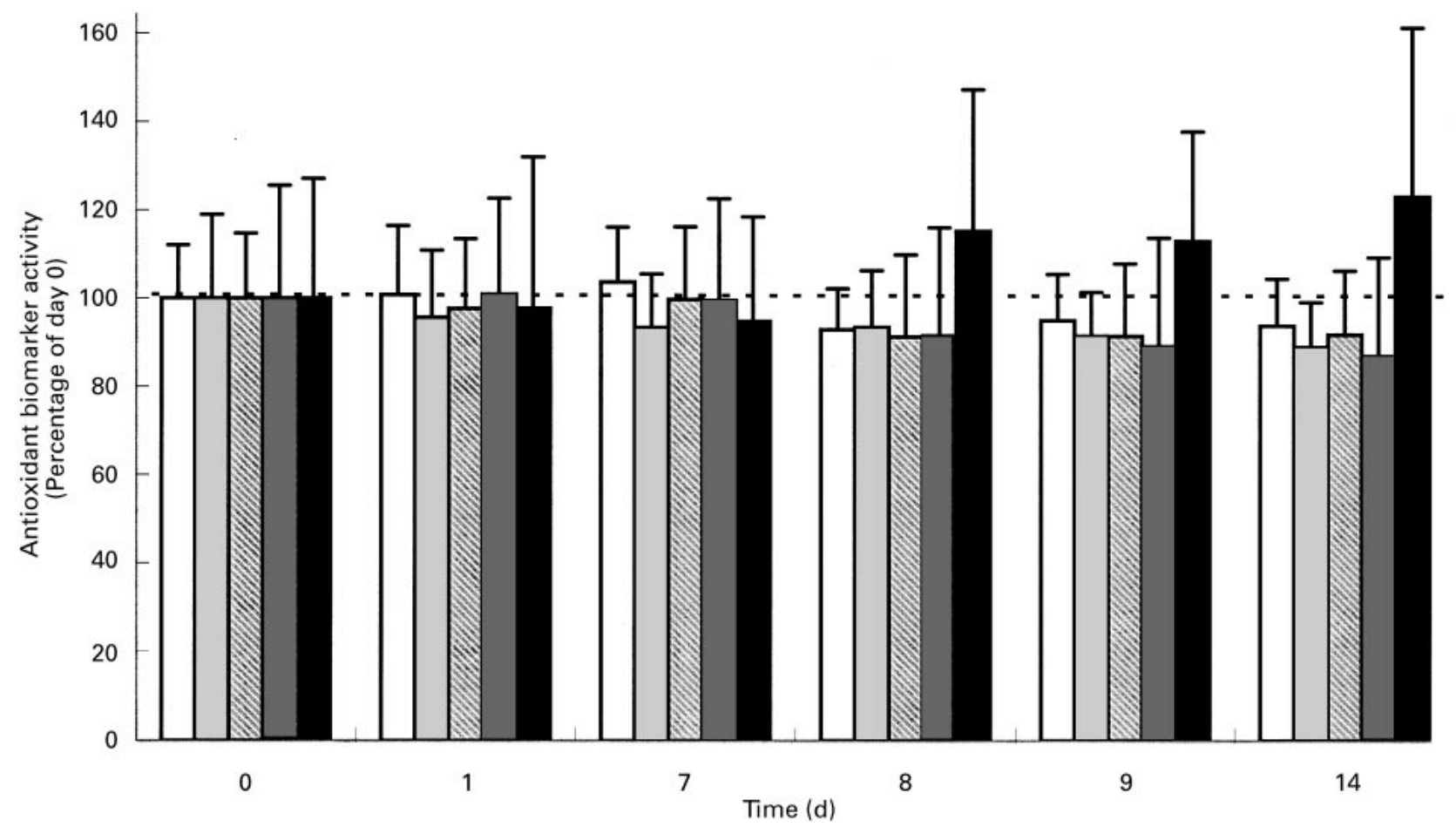

Fig. 3. Percentage change in the activities of antioxidant biomarkers on selected days during a 2-week intervention period when subjects

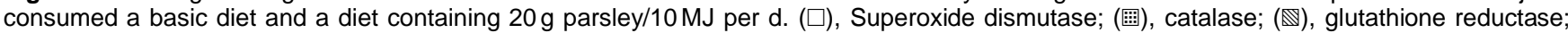
(図), glutathione peroxidase; ( $\mathbf{\square})$, 2-adipic semialdehyde. Values are means for fourteen subjects, with their standard errors represented by vertical bars. Trends for superoxide dismutase, catalase, glutathione reductase and glutathione peroxidase were significant by multivariate ANOVA $(P<0.01)$.

apigenin intake was excreted with urine in $24 \mathrm{~h}$. We previously investigated the excretion of quercetin from a mixture of blackcurrant and apple juice (Young et al. 1999) and found an excretion of $0.47 \%$ of the dose with an estimated elimination half-life of $24 \mathrm{~h}$, which was in accordance with previous studies (Hollman et al. 1997). Thus, the fraction of apigenin excreted with urine is apparently similar to the fraction of quercetin excreted with urine, but the elimination half-life seems to be shorter, only about $12 \mathrm{~h}$.

In the present study, significant inter-individual variation in the excretion of apigenin was observed, and apparently the bioavailability of apigenin is high in some selected individuals, probably due to variations in intestinal physiology. Apigenin is primarily present in parsley as apiin, the 7-O-apioside of apigenin. Although studies suggest that some flavonoid glucosides may be absorbed readily (Hollman et al. 1995), previous investigations have shown that generally, the flavonoid glycosides have to be hydrolysed by the micro-organisms in the gut before absorption (Kühnau, 1976). In accordance with our results, Hollman et al. (1997) also reported a few individuals who excreted considerably higher levels of quercetin after administration of rutin (the 3-O-rutinoside of quercetin), indicative of a more efficient hydrolysis of rutinosides in the colon of these subjects.

Intervention with parsley for 1 week produced an increase in the activity of two antioxidant enzymes, GR and SOD, in the crossover study. Short-term changes in these enzymes have previously been reported (Saghir et al. 1997). It was recently shown that an individual's reference data for SOD and Gpx are probably more useful than population-based data due to high intra-individual variations in the activity of these enzymes (Lux \& Naidoo, 1995). We observed a strong positive correlation at the individual level between increases in CAT and SOD after parsley intervention and also a strong correlation with decreases in protein oxidation. The opposite effect, a higher level of plasma protein oxidation and lower activities of SOD and CAT, has previously been reported in a cross-sectional study of bus drivers exposed to high levels as compared with low levels of traffic exhaust fumes, known to contain many pro-oxidants (Daneshvar, 1996). This might indicate that these biomarkers of oxidative stress are related, and that parsley intervention decreased oxidative stress in some of the volunteers.

Erythrocyte SOD has been suggested to be associated with the Cu status in individuals (Belsten \& Wright, 1995; Milne \& Nielsen, 1996). Since the calculated $\mathrm{Cu}$ content in the basic diet $(1.06 \mathrm{mg} / 10 \mathrm{MJ})$ was found to be similar to the normal Danish intake of this trace element (Bro et al. 1990), changes in the $\mathrm{Cu}$ intake during intervention probably cannot explain the observed effects on SOD. Neither can the intake of parsley have contributed to a change in $\mathrm{Cu}$ intake, since the $\mathrm{Cu}$ content of parsley is reported to be only $0.09 \mathrm{mg} / 100 \mathrm{~g}$ fresh weight (Møller, 1996).

In the present study we also observed an overall decrease with time in the activity of all antioxidant enzymes during the whole crossover study, when flavonoid-rich foods except parsley were excluded. A similar decrease in SOD 
was reported in a controlled study of women living in a dietary unit after a $68 \mathrm{~d}$ depletion of carotenoid-rich foods, whereas repletion with $\beta$-carotene was found to normalize enzyme levels after $28 \mathrm{~d}$ (Dixon et al. 1994). Since $\beta$ carotene was not depleted in the present study, other factors may be responsible. Intakes of the flavonoid apigenin, but also of the carotenoid lutein, increased with parsley intervention. The non-significant positive correlation of SOD and Gpx activities with apigenin excretion might indicate a role for this flavonoid in modulation of key antioxidant enzymes. However, it cannot be excluded that other components in parsley, e.g. lutein or furocoumarins, or a combination of parsley constituents, are responsible for the effects seen on the antioxidant enzymes. It can be speculated that lowered intakes of certain fruits or green vegetables, which are good sources of both flavonoids and carotenoids, may lead to an overall decreasing trend in antioxidant enzymes.

In conclusion, apigenin is absorbed from parsley, and excreted in low amounts, $0.58 \%$ on average, with urine. Large variations in the fraction of apigenin excreted with urine were observed among the subjects, probably due to differences in the efficiency of absorption. Since identical intakes of parsley resulted in very different apigenin excretion levels among individuals, urinary apigenin might be a useful biomarker for apigenin absorption in human studies.

The parsley intervention resulted in significant increases in the two antioxidant enzymes, GR and SOD. Furthermore, the overall decrease with time in the activity of all antioxidant enzymes during the total intervention regardless of diet could have been due to the low intake of fruits and green vegetables.

\section{Acknowledgements}

Financial support was obtained by a Danish Food Technology Research grant (FOETEK 2) from the Danish Research Councils to the project Health and Nutritional Aspects of Novel Foods, Novel Antioxidants of Plant Origin. The authors wish to thank the laboratory technicians Anni Schou, Vibeke Kegel, and Ella Jessen for excellent assistance.

\section{References}

Ameer B, Weintraub RA, Johnson JV, Yost RA \& Rouseff RL (1996) Flavanone absorption after naringin, hesperidin, and citrus administration. Clinical Pharmacology and Therapeutics 60, 34-40.

Armitage P \& Berry G (1994) Statistical Methods in Medical Research, 3rd ed. Cambridge: Blackwell Science Ltd.

Belsten JL \& Wright AJ (1995) European community-FLAIR common assay for erythrocyte superoxide dismutase (SOD); results of an inter-laboratory trial. European Journal of Clinical Nutrition 49, 928-931.

Birt DF, Mitchell D, Gold B, Pour P \& Pinch HC (1997) Inhibition of ultraviolet light-induced skin carcinogenesis in SKH-1 mice by apigenin, a plant flavonoid. Anticancer Research 17, 85-91.

Bro S, Sandström B \& Heydorn K (1990) Intake of essential and toxic trace elements in a random sample of Danish men as determined by the duplicate portion sample technique. Journal of Trace Elements and Electrolytes in Health and Disease 4, $147-155$.

Daneshvar B (1996) Biomarkers for oxidative damage to proteins. Development of analytical methods and their application to biological samples. $\mathrm{PhD}$ Thesis, Institute of Pharmacology, University of Copenhagen, Denmark.

Daneshvar B, Frandsen H, Autrup H \& Dragsted LO (1997) Gamma-glutamyl semialdehyde and 2-amino-adipic semialdehyde: biomarkers of oxidative damage to proteins. Biomarkers 2, 117-123.

Dixon ZR, Burri BJ, Clifford A, Frankel EN, Schneeman BO, Parks E, Keim NL, Barbieri T, Wu MM, Fong AK, Kretsch MJ, Sowell AL \& Erdman JW Jr (1994) Effects of a carotenedeficient diet on measures of oxidative susceptibility and superoxide dismutase activity in adult women. Free Radical Biology and Medicine 17, 537-544.

Fernandez de Simon B, Perez Ilzarbe J, Hernandez T, Gomez Cordoves C \& Estrella I (1992) Importance of phenolic compounds for the characterization of fruit juices. Journal of Agricultural and Food Chemistry 40, 1531-1535.

Fraga CG, Martino VS, Ferraro GE, Coussio JD \& Boveris A (1987) Flavonoids as antioxidants evaluated by in vitro and in situ liver chemiluminescence. Biochemical Pharmacology 36, 717-720.

Hart DJ \& Scott KJ (1995) Development and evaluation of an HPLC method for the analysis of carotenoids in foods, and the measurement of the carotenoid content of vegetables and fruits commonly consumed in the UK. Food Chemistry 54, 101-111.

Hollman PCH, van der Gaag MS, Mengelers MJB, van Trijp JMP, de Vries JHM \& Katan MB (1996) Absorption and disposition kinetics of the dietary antioxidant quercetin in man. Free Radical Biology and Medicine 21, 703-707.

Hollman PCH, van Trijp JMP, Buysman MNCP, van der Gaag MS, Mengelers MJB, Vries JHM \& Katan MB (1997) Relative bioavailability of the antioxidant flavonoid quercetin from various foods in man. FEBS Letters 418, 152-156.

Hollman PCH, Vries JHM, van Leeuwen SD, Mengelers MJB \& Katan MB (1995) Absorption of dietary quercetin glycosides and quercetin in healthy ileostomy volunteers. American Journal of Clinical Nutrition 62, 1276-1282.

Janssen K, Mensink RP, Cox FJJ, Harryvan JL, Hovenier R, Hollman PCH \& Katan MB (1998) Effects of the flavonoids quercetin and apigenin on hemostasis in healthy volunteers: results from an in vitro and a dietary supplement study. American Journal of Clinical Nutrition 67, 255-262.

Justesen U, Knuthsen P \& Leth T (1998) Quantitative analysis of flavonols, flavones, and flavanones in fruits, vegetables and beverages by HPLC with photodiode array and mass spectrometric detection. Journal of Chromatography A 799, 101-110.

Kühnau J (1976) The flavonoids. A class of semi-essential food components: their role in human nutrition. World Review of Nutrition and Dietetics 24, 117-191.

Kuo ML, Lee KC \& Lin JK (1992) Genotoxicities of nitropyrenes and their modulation by apigenin, tannic acid, ellagic acid and indole-3-carbinol in the Salmonella and CHO systems. Mutation Research 270, 87-95.

Lee SJ, Son KH, Chang HW, Do JC, Jung KY, Kang SS \& Kim HP (1993) Antiinflammatory activity of naturally occurring flavone and flavonol glycosides. Archives of Pharmacology Research 16, 25-28.

Lux O \& Naidoo D (1995) Biological variability of superoxide dismutase and glutathione peroxidase in blood. Redox Report $\mathbf{1}$, 331-335.

Milne DB \& Nielsen FH (1996) Effects of a diet low in copper on copper-status indicators in postmenopausal women. American Journal of Clinical Nutrition 63, 358-364.

Møller A (1996) Levnedsmiddeltabeller (The Composition of Foods), 4th revised and extended ed. [E Saxholt, editor]. Copenhagen: National Food Agency of Denmark.

Nielsen SE \& Dragsted LO (1998) Column-switching highperformance liquid chromatographic assay for determination 
of apigenin and acacetin in human urine with ultraviolet absorbance detection. Journal of Chromatography B 713, 379-386.

Pocock SJ (1998) Clinical trials. A practical approach. Chichester: John Wiley \& Sons.

Saghir AN, Rickards H \& Pall HS (1997) Postprandial changes in superoxide dismutase activity in subjects with Gilles de la Tourette syndrome and controls. Experimental Neurology 144, 420-422.

Tschiersch K \& Hölzl J (1993) Resorption und Ausscheidung von Apigenin, Apigenin-7-glucosid und Herniarin nach Peroraler Gabe eines Extract von Matricaria recutita (L.) [syn. Chamomilla recutita (L.) Rauschert] (Absorption and excretion of apigenin, apigenin-7-glycoside and herniarin after oral administration of extracts of Matricaria recutita). Pharmazie 48, 554-555.

van Acker SABE, van den Berg DJ, Tromp MNJL, Griffioen DH, van Bennekom WP, van der Vijgh WJF \& Bast A (1996)
Structural aspects of antioxidant activity of flavonoids. Free Radicical Biology and Medicine 20, 331-342.

Wei H, Tye L, Bresnick E \& Birt DF (1989) Inhibitory effect of apigenin, a plant flavonoid, on epidermal ornithine decarboxylase and skin tumor promotion in mice. Cancer Research 50, 499502.

Wheeler CR, Salzman JA, Elsayed NM, Omaye ST \& Korte DW Jr (1990) Automated assay for superoxide dismutase, catalase, glutathione peroxidase, and glutathione reductase. Analytical Biochemistry 184, 193-199.

Young JF, Nielsen SE, Haraldsdóttir J, Daneshvar B, Lauridsen ST, Knuthsen P, Crozier A, Sandström B \& Dragsted LO (1999) Effect of juice intake on urinary quercetin excretion and biomarkers of antioxidative status. American Journal of Clinical Nutrition 69, 87-94. 